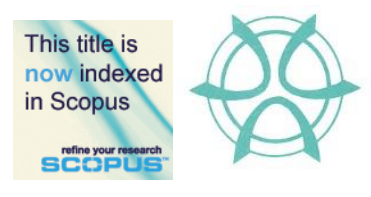

PLANNING MALAYSIA:

Journal of the Malaysian Institute of Planners

VOLUME 15 VOLUME 1 (2017), 305 - 318

\title{
BIBLIOMETRIC ANALYSIS ON QUANTIFYING URBAN SPRAWL IN ASSESSING A COMPREHENSIVE MEANING OF SPRAWL: A REVIEW
}

\author{
Nur Aulia Rosni ${ }^{1}$, Norzailawati Mohd Noor ${ }^{2}, \&$ Alias Abdullah ${ }^{3}$ \\ ${ }^{1,2,3}$ Kulliyyah of Architecture \& Environmental Design \\ INTERNATIONAL ISLAMIC UNIVERSITY MALAYSIA
}

\begin{abstract}
After more than half century has passed, urban sprawl remains as one of the most important and unresolved matters in the urban development process. This paper adopts "Bibliometrics Analysis" technique, which is a statistical analysis of scientific publications to review the studies on urban sprawl from the year 1996 till 2015 in order to identify the fundamental issues and problem of urban sprawl. This method allows the researcher to review the literature of topic of interest critically, not only based on national and international networks but includes the multi-disciplinary fields of science and technology relating to urban planning. The publications on urban sprawl were retrieved from the two largest scientific databases namely Scopus and ScienceDirect. The sampling of publications was based on the "Most Cited Articles" indicator. The findings on urban sprawl issues and problems are presented in four categories, which are the lack of consensus in defining urban sprawl, unavailability of method to quantify urban sprawl, access to data and tools, and varying urban sprawl patterns based on area. The findings of this study provide the gap for future research on urban sprawl.
\end{abstract}

Keyword: Urban sprawl, sprawl issues and problem, urban sprawl planning, bibliometric analysis.

Date Received: $30^{\text {th }}$ April 2016

Date of Acceptance: $30^{\text {th }}$ October 2016 
Nur Aulia Rosni, Norzailawati Mohd Noor, \& Alias Abdullah

Bibliometric Analysis on Quantifying Urban Sprawl in Assessing a Comprehensive Meaning of Sprawl: A Review

\section{INTRODUCTION}

The paper uses "Bibliometrics Analysis" technique to analyse research publications on urban sprawl topic ranging from 1996 till 2015 in order to extract the relevant issues and problems of urban sprawl. Since the term became apparent in the 1950s, "Urban Sprawl" has been globally studied by researchers from various backgrounds and interests. Unfortunately, even after a few decades have passed, the definitive way to define urban sprawl is still absent. Urban sprawl is a fundamental issue in modern urban development since its rapid, but uncontrolled expansion is alarming for many professionals in the built environment (Altieri et al., 2014; Arribas-Bel, Nijkamp \& Scholten, 2011). Some researchers agree that urban sprawl is something undesirable and have more negative impact rather than positive consequences (Ewing, 2008; Ewing et al., 2016; Ewing, Pendall \& Chen, 2002; Knaap et al., 2005). Urban sprawl is a broad term involving different characteristics and types, and caused by various factors, thus different approaches are needed to address them (Majid \& Yahya, 2010, 2011). Advocating for certain development concept or planning policies may not necessarily be successful without initially knowing the key issues and problem of sprawl faced by a city (Chorianopoulos et al., 2010; Habibi \& Asadi, 2011).

\section{THEORETICAL REVIEW ON URBAN SPRAWL}

According to $\mathrm{Wu}$ (2006), a city is a highly complex socio-economic and spatial entities with a distinct hierarchical order. It is a hub of almost all human activities (Rajeshwari, 2006). Apart from physical forms, cities are shaped by various development forces such as economic, political, cultural and social, which later imposing themselves in physical forms and closely relate to urban sprawl (Apostolos, 2007; Ardeshiri \& Ardeshiri, 2011).

In Western countries, urban development is characterized by two important processes which are the inner-city decline and urban sprawl. These two processes are in fact interrelated as urban sprawl accelerates the inner-city decline. Bhatta, Saraswati and Bandyopadhyay (2010b) consider "Urban Growth" and "Urbanisation" are both the processes of "Urban Development." Meanwhile, urban growth and urbanisation as defined by EEA (2006) are "the increase in the number of people living in towns and cities" and "the proportion of a country that is urban". The process has a high impact on the environment such as depletion of natural resources, landscape deterioration, pollution and climate changes (Olujimi, 2009; Ramachandra, Bharath \& Sowmyashree, 2014; Weng, 2001).

Based on the growing awareness of the public on the uncontrolled urban development issues, it is vital to improve understanding of this phenomena and their underlying causes (Rajeshwari, 2006; Verbeek, Boussauw \& Pisman, 2014). However, some scholars also argue that urban sprawl is inherent to city growth and that it will always continue to be a side effect of urban development process 
PLANNING MALAYSIA:

Journal of the Malaysia Institute of Planners (2017)

(Steil, Salingaros \& Mehaffy, 2007; Almeida, 2005; Bhatta, Saraswati \& Bandyopadhyay, 2010b; Altieri et al., 2014). Thus, what is required is not halting urban sprawl but to lessen its negative impacts in order to promote sustainable development (Steil, Salingros \& Mehaffy, 2001).

Sprawl has become a characteristic of urban development worldwide. Urban sprawl has became one of the most important issues in the urban area around the world since the twenty-first century whose importance is still growing today (Altieri et al., 2014; Arribas-Bel, Nijkamp \& Scholten, 2011). Its rapid and uncontrolled expansion are alarming for many professionals including planners, urban specialists, statisticians, engineers and decision makers Arribas-Bel, Nijkamp \& Scholten, 2011; Bruegmann, 2015; Ewing, Pendall \& Chen, 2002). On the contrary, sustainable development concept espouses development that meets the requirements of the present without conceding the capability of upcoming generations to meet theirs. (Ardeshiri \& Ardeshiri, 2011; Tanguay et al., 2010). The sustainable development concept has become increasingly significant for creating a better future for the world, economically, socially and environmentally (Arbury, 2005). As a result, this concept depends on the future role of urban planning in handling urban sprawl issues (Catalán, Saurí \& Serra, 2008; Yeh, 2000).

\section{METHODOLOGY}

Bibliometric analysis was used to obtain reliable information on urban sprawl issues and problems. Bibliometric analysis offers a powerful set of methods and measures for studying the structure and process of scholarly communication. Besides, this method is expected to play an increasingly important role in research assessment and management (Campbell et al., 2010; Bellis, 2009; Borgman \& Furner, 2002). Also, bibliometric indicators which quantify the production and use of bibliographic material, have been used extensively in the assessment of research performance (Russell \& Rousseau, 2010; Campbell et al., 2010; Bellis, 2009; Reuters, 2008). The scientific databases used to collect journals and articles include Scopus, ScienceDirect, and Web of Science ranging from the year 1996 to 2015 (20 years) as the principle search parameter. Specific keywords were retrieved from the title and abstract of each journal and article using Boolean Searching technique for urban sprawl publications of different subject areas. The enormous numbers of publications for this topic were then limited by "Most Cited Paper" for each year making the final document analysed pertinent to the interest of this paper only 100 records from all databases. Based on the selected publications, a detail and comprehensive analysis on the content of the literature review was conducted using content analysis technique to extract the issues and problems of sprawl.

The results from Bibliometric analysis not only provides valuable information on the scientific trend and pattern of urban sprawl studies but assist 
Nur Aulia Rosni, Norzailawati Mohd Noor, \& Alias Abdullah

Bibliometric Analysis on Quantifying Urban Sprawl in Assessing a Comprehensive Meaning of Sprawl: A Review

the researcher in indicating the most important and relevant issues and problems associated with urban sprawl for the last 20 years. The findings were discussed into four categories of challenges namely (i) urban sprawl, (ii) geospatial indices, (iii) GIS and remote sensing, lastly on (iv) the different urban context. The identified issues and problems stand as the gap in determining urban land use sprawl through geospatial indices measurement method using GIS and remote sensing.

\section{ANALYSIS AND FINDINGS}

The term "Urban Sprawl" is a concept that is vague in its definition. Despite being vigorously researched into, urban sprawl remains to be without a universally accepted and well-established definition (Altieri et al., 2014; Arribas-Bel, Nijkamp \& Sholten, 2011; Barnes et al., 2001; Bhatta, 2010; Bhatta, Saraswati \& Bandyopadhyay, 2010a, 2010b; Bruegmann, 2015). Bibliometric analysis on urban sprawl publications (Table 1) shows that publications on urban sprawl topic have been increasing since 1996. This indicates a growing awareness among academicians and professionals on urban sprawl. However, publications that emphasise on defining urban sprawl are still lacking. For over 20 years, only $20 \%$ of the publications focus on defining urban sprawl. The lowest publication on urban sprawl studies is from medicine subject area (4.1\%), business, management and accounting (4.8\%), and economics, econometrics and finance (5.6\%), proving that there is some form of disregard of urban sprawl importance in some subject areas.

Lack of awareness on sprawl issues from some areas cause the efforts to contain sprawl sometimes resulted in increasing another (Coisnon, Oueslati \& Salani, 2014, 2012; Galster et al., 2001; Gottlieb, 1999; Ngoran \& Xue, 2015; Wu et al., 2006). Besides, the analysis of the pattern of urban sprawl publications also indirectly explain why there are so many unintegrated methods and tools to measure sprawl. In terms of the urban context, the United States is the leading country in the urban sprawl research with 1,127 documents published in 20 years period. The publication gap between the Unites States and China (391) is 736 publications. The huge difference proves that urban sprawl issues first acknowledged and conducted in the United States. Most of literature and debates on urban sprawl also have been based on the US experience (Chorianopoulos et al., 2010; Habibi \& Asadi, 2011; Nechyba \& Walsh, 2004; Travisi, Camagni, \& Nijkamp, 2009). China is taking the lead in the context of Asian Countries, followed by India (91 publications) and Japan (49 publications). Countries with a low number of research publications are either developing or third world countries that faced problem such as over-populated, slum area, congestion and apparently sprawling. 
PLANNING MALAYSIA:

Journal of the Malaysia Institute of Planners (2017)

Table 1 Publications on Urban Sprawl

\begin{tabular}{lcccc|ccc}
\hline \multicolumn{5}{c}{ Urban Sprawl } & \multicolumn{3}{c}{ Urban Sprawl Definition } \\
\hline & Year & Scopus & $\begin{array}{c}\text { Science } \\
\text { Direct }\end{array}$ & $\begin{array}{c}\text { Web of } \\
\text { Science }\end{array}$ & Scopus & $\begin{array}{c}\text { Science } \\
\text { Direct }\end{array}$ & $\begin{array}{c}\text { Web of } \\
\text { Science }\end{array}$ \\
\hline $\mathbf{1 .}$ & $\mathbf{2 0 1 5}$ & 314 & 821 & 132 & 8 & 379 & 9 \\
$\mathbf{2 .}$ & $\mathbf{2 0 1 4}$ & 331 & 663 & 136 & 8 & 278 & 7 \\
$\mathbf{3 .}$ & $\mathbf{2 0 1 3}$ & 310 & 661 & 111 & 8 & 290 & 8 \\
$\mathbf{4 .}$ & $\mathbf{2 0 1 2}$ & 296 & 562 & 98 & 9 & 250 & 1 \\
$\mathbf{5 .}$ & $\mathbf{2 0 1 1}$ & 265 & 404 & 90 & 5 & 160 & 6 \\
$\mathbf{6 .}$ & $\mathbf{2 0 1 0}$ & 238 & 316 & 87 & 3 & 151 & 2 \\
$\mathbf{7 .}$ & $\mathbf{2 0 0 9}$ & 202 & 373 & 90 & 4 & 148 & 2 \\
$\mathbf{8 .}$ & $\mathbf{2 0 0 8}$ & 217 & 339 & 63 & 5 & 150 & 1 \\
$\mathbf{9 .}$ & $\mathbf{2 0 0 7}$ & 170 & 261 & 55 & 4 & 105 & 1 \\
$\mathbf{1 0 .}$ & $\mathbf{2 0 0 6}$ & 143 & 259 & 41 & 4 & 110 & 1 \\
$\mathbf{1 1 .}$ & $\mathbf{2 0 0 5}$ & 147 & 186 & 36 & 12 & 76 & 3 \\
$\mathbf{1 2 .}$ & $\mathbf{2 0 0 4}$ & 118 & 212 & 35 & 4 & 77 & 2 \\
$\mathbf{1 3 .}$ & $\mathbf{2 0 0 3}$ & 108 & 158 & 17 & 7 & 68 & 5 \\
$\mathbf{1 4 .}$ & $\mathbf{2 0 0 2}$ & 81 & 135 & 17 & 3 & 56 & 1 \\
$\mathbf{1 5}$ & $\mathbf{2 0 0 1}$ & 86 & 173 & 26 & 3 & 64 & 3 \\
$\mathbf{1 6 .}$ & $\mathbf{2 0 0 0}$ & 57 & 107 & 12 & 1 & 37 & 1 \\
$\mathbf{1 7 .}$ & $\mathbf{1 9 9 9}$ & 37 & 63 & 7 & 0 & 24 & 0 \\
$\mathbf{1 8 .}$ & $\mathbf{1 9 9 8}$ & 37 & 72 & 7 & 1 & 27 & 1 \\
$\mathbf{1 9}$ & $\mathbf{1 9 9 7}$ & 25 & 106 & 4 & 0 & 47 & 0 \\
$\mathbf{2 0 .}$ & $\mathbf{1 9 9 6}$ & 25 & 92 & 5 & 0 & 39 & 0 \\
\hline TOTAL & $\mathbf{3 , 2 0 7}$ & $\mathbf{5 , 9 6 3}$ & $\mathbf{1 , 0 6 9}$ & $\mathbf{8 9}$ & $\mathbf{2 , 5 3 6}$ & $\mathbf{5 6}$ \\
\hline & & $\mathbf{1 0 , 2 3 9}$ & & & $\mathbf{2 , 6 7 9}$ & \\
\hline
\end{tabular}

Sources: Scopus, ScienceDirect, WoS

\section{DISCUSSION OF ISSUES AND PROBLEMS}

\section{Urban Sprawl}

\section{Unavailability of agreeable definition for the term}

Urban sprawl is a term that has a long history in the academic and development practice. Nonetheless, it is still widely discussed as a major problem today (Coisnon, Oueslati \& Salani 2014). Surprisingly, a standard and precise definition of urban sprawl is still not existed (Altieri et al., 2014; Bruegmann, 2015; Terzi \& Kaya, 2008; Theobald, 2003; Wilson et al., 2003). Bhatta, Saraswati and Bandyopadhyay (2010a) claim urban sprawl as a concept suffers from difficulties in the definition. Hammer and Witten (2011) question if there is a single widely accepted definition of sprawl on which the majority of stakeholders can agree. Hasse and Kornbluh (2004) add that there is a need to better define the term to focus specifically on the undesirable and problematic development that many stakeholders are arguing. 
Nur Aulia Rosni, Norzailawati Mohd Noor, \& Alias Abdullah

Bibliometric Analysis on Quantifying Urban Sprawl in Assessing a Comprehensive Meaning of Sprawl: A Review

According to Ewing (2008), Ewing, Pendall and Chen (2002, and Galster et al. (2001), most people especially professionals may recognise sprawl when they see it, but this may not be helpful in practice especially in the rule or decision making. Currently, sprawl has been loosely defined as dispersed and inefficient urban growth that is always associated with characteristic such as low-density, decentralization and fragmentation (Farber \& Li, 2013; Hasse \& Lathrop, 2003). Without a universal definition, quantification and modelling of urban sprawl are difficult (Bhatta, Saraswati \& Bandyopadhyay, 2010b; Wilson et al., 2003). Moreover, Bruegmann (2015) also states that there has been a significant debate in academia on how to measure sprawl and to understand its dynamics, thus a universal definition of urban sprawl is required.

\section{Ambiguous ways in determining the urban sprawl concept}

Urban sprawl is a critical issue in today's world. While being a manifestation of development, it is known for its negative environmental and social impacts (Crawford, 2007; Feng et al., 2015). Over the years, urban sprawl concept has been defined in many ways by many different groups with each definition seemingly only serving each particular group's interest (Haase \& Nuissl, 2007; Hammer \& Witten, 2011; Ngoran \& Xue, 2015). As a matter of fact, not all urban growth is considered as sprawl and one person's sprawl can be another person's solution to sprawl (Almeida, 2005; Gottlieb, 1999). Numerous studies have revealed the nature of urban sprawl and the reasons for its occurrence in different contexts (Coisnon, Oueslati \& Salani, 2014). Much of the confusion about sprawl, especially on causes, consequences and conditions, stems from the conflation of ideology, experience, and effects (Galster et al., 2001).

\section{Universality: Sprawl from a broader context}

As pointed out earlier, the term "urban sprawl" is loose and ambiguous. It can be seen that urban sprawl is not only important issue for urban specialists, planners, and statisticians, but this issue expanded to the mainstream. The rapid and uncontrolled urban expansion in the world is alarming, both in developed and developing countries (Altieri et al., 2014; Banzhaf \& Lavery, 2010; Bruegmann, 2015; Wassmer, 2007). However, this variety of views and understandings on the matter may also enrich the analysis if performed universally (Arribas-Bel, Nijkmap \& Scholten, 2011; Barnes et al., 2001). Urban development process without sufficient understanding of its wider context leads to inadequate interpretations of sprawl and its impact (Altieri et al., 2014; Bhatta, Saraswati \& Bandyopadhyay, 2010b; Chorianopoulos et al., 2010). Ewing (1997) prove that there are different standpoint of viewing and defining urban sprawl from town planners and economists perspectives. Anas and Pines (2008) and Vyn, (2012) explore the idea of studying the relationship between different aspect of sprawls 
that proved unintegrated development policies might reduce sprawl in one aspect but increase in another.

\section{Other issues and problem associated with urban sprawl}

Urban sprawl is a serious challenge for urban management and planning in many countries (Gennaio, Hersperger \& Burgi, 2009). Assessment of the environmental and socio-economic impact of sprawl fails to find the solution and is still a subject of debate (Haase \& Nuissl, 2007). Furthermore, many urban management strategies for sustainable development such as compact city, smart growth and green city concept contradict one another and failed to curb sprawl comprehensively (Arbury, 2005; Ardeshiri \& Ardeshiri, 2011). Besides, urban sprawl has contributed to the deterioration of the quality of life. A study by Ewing et al. (2014) shows that adults living in sprawling counties have a higher body mass index (BMI) and are more likely to be obese than are their counterparts living in compact cities.

Sprawl is widely discussed but poorly understood. It may mean different things to different people. However, most observers seem to agree that sprawl can be characterized by a fragmented pattern of land development ( $\mathrm{Wu}, 2006)$. However, Gottlieb (1999) claims that many economists do not see sprawl as a problem nor acknowledge its existence because the fragmented pattern of city growth is a result of fair-market being in operation. Many economists also argue that sprawl occurs due to market failures and lack of useful integrated economic model (Anas \& Rhee, 2006; Brueckner \& Helsley, 2011; Nechyba \& Walsh, 2004). In contrast, urban planners and policy makers favour land use controls that directly limit the expansion of cities and encourage high-density development in central cities, which are widely presumed to reduce sprawl (Ewing, 1997).

\section{Geospatial Indices \\ Distinguishing urban development from urban sprawl}

As urban development occurs, its growth is often confused with urban sprawl. Ewing (2008) suggests that there are three dimensions associated with urban development namely land use, density and time. The same dimensions also apply to sprawl. However, to what extend the growth is dispersed or compact remain as a problem (Almeida, 2005; Burchfield et al., 2006; Tsai, 2005). Additionally, understanding on urban sprawl, especially in Asian countries, still heavily relies on qualitative discussion instead of quantitative analysis (Feng, 2008). Some scholars propose that urban sprawl needs to be quantitatively measured in order to determine whether it is on the rise or decline, and whether it is a recent occurrence or has been evident for a long time (Gerundo \& Grimaldi, 2011; Bruegmann, 2015). 
Nur Aulia Rosni, Norzailawati Mohd Noor, \& Alias Abdullah

Bibliometric Analysis on Quantifying Urban Sprawl in Assessing a Comprehensive Meaning of Sprawl: A Review

\section{Limitation in capturing the characteristics of urban sprawl in measurement}

As mentioned earlier, many definitions use characteristics such as low density or dispersed development to identify urban sprawl. However, these features are not adequately defined or explained, nor these can comprehensively determine urban sprawl (Ardeshiri \& Ardeshiri, 2011; Couch \& Karecha, 2006). As different factors caused various types of sprawl, different approaches are required to address them. Any measures taken without first knowing what kinds of sprawl the city is facing may not necessarily work (Majid \& Yahya, 2010; Verbeek et al., 2014). Numerous researches were dedicated to the measurement or urban form, but they have limitations in capturing the overall characteristics of urban sprawl. (Almeida, 2005; Jaeger, Bertiller, Schwick, Cavens \& Kienast, 2010; Jaeger, Bertiller, Schwick \& Kienast, 2010; Li \& Yeh, 2004; Steil, Salingaros \& Mehaffy, 2007; Yeh \& Li, 1999a, 1999b). Bhatta, Saraswati and Bandyopadhyay (2010a) assert that effective way to identify sprawl can never be achieved without first defining its solid characterisations. However, this is not an easy task since previous researches on characterising sprawl have either failed to draw a conclusion or cannot be universally implemented.

\section{Managing urban sprawl from different geographical background}

According to Ewing et al. (2016), there is rather limited researches that explore the global characteristics of urban development and urban sprawl as well as their implications for equity and sustainable development. Gennaio, Herperger and Burgi (2009) relate this problem to the difficulties in comparing the international urban development due to diverse databases. They found that different countries have different databases and in many cases, the data is different between cities, counties and states of the same country.

\section{GIS and Remote Sensing Application Availability of routinely update database}

Frequent monitoring of urban sprawl is needed to limit the impact of this phenomenon towards the environment. Thus regularly updated data is required for that purpose Altieri et al., 2014; Durieux, Lagabrielle \& Nelson, 2008). As highlighted beforehand, there are not many quantitative contributions in urban sprawl research as compared to the qualitative discussion. One probable reason for this scenario is the limited availability of good and reliable data (Arribas-Bel, Nijkamp \& Scholten, 2011). Information on urban development especially in developing cities is often unavailable, due to their rapid development and capacity constraints of planning authorities to keep track. The ability to assess, measure and monitor sprawl depend on the availability of relevant, accurate and reliable data (Altieri et al., 2014; Belal \& Moghanm, 2011; Bhatta, Saraswati \& Bandyopadhyay, 2010b; Feng, 2008; Herold, Couclelis \& Clarke, 2005; Osman, Nawawi \& Abdullah, 2008). 


\section{Lack of synchronizing tools/methods to control urban sprawl}

Allen and Lu (2003) state that modelling and predicting urban growth has begun in the 1950s, but slowed down during 1970 s to 1980 s. Recent availability and improvement of spatial data combined with the advancement of geographic information system and computer technologies, the activities have again increased since the 1990s till now. However, there are still very few methods used to assist in the identification and monitoring of urban sprawl in development areas. Therefore, there is a clear need for such method to be used with geospatial databases from GIS and remote sensing data (Altieri et al., 2014). Anas and Pines (2008) argue that if local urban planners and decision makers were to use uncoordinated land use policies that are generated based on less accurate data and inadequate evaluation methods, the overall urban sprawl rate may increase and cause shuffling of population among neighbouring cities. Last but not least, the recent demand for the data with high resolution and accuracy as well as the latest technology of geospatial tools. The high cost of data acquisition and tools used to process the data has affected the stages in conducting research and the quality of outcomes (Gamba, 2009).

\section{Urban Context}

\section{Excessive concentration on urban sprawl experience from specific urban context}

Many researchers have come to conclude that modern debates on the urban form and urban sprawl have become influenced strongly by the result of an excessive concentration on American experiences, hence, leading to neglecting of experience from urban context of other countries. Urban sprawl occurrence varies in different context due to various economic, geographic, environmental, social and political situations (EEA, 2006; Castracane et al., 2003; Catalán, Sauri \& Serra, 2008; Chorianopoulos et al., 2010; Couch \& Karecha, 2006; Habibi \& Asadi, 2011; Nechyba \& Walsh, 2004). Most of the developing countries particularly in Asia suffer the absent of clear quantitive approaches to indicate sprawl and way to evaluate the extent of its growth (Feng, 2008). Moreover, there is a growing awareness from researchers in Europe, Asia and Africa on the issue where majority of the literature on sprawl focuses on American urban areas (Travisi, Camagni \& Nijkamp, 2009). Based on the bibliometric analysis conducted for this research, it can be seen that as of 2015, the United States of America has the highest number of published literature on sprawl. For Asian countries, China and India are taking the leads while Malaysia is still in infancy stage. Osman, Nawawi and Abdullah (2008) proclaim that in Malaysia, there is relatively low visibility of urban issues and there seemed to be many lingering problems which were the outcome of the urban development process for the past thirty years. The development process influenced by globalisation and economic 
Nur Aulia Rosni, Norzailawati Mohd Noor, \& Alias Abdullah

Bibliometric Analysis on Quantifying Urban Sprawl in Assessing a Comprehensive Meaning of Sprawl: A Review

competitiveness factors that seen many main cities as economic growth engines, so the control of its previous expansion almost not exists. The intensification of urban sprawl within the three top Malaysia's metropolitan areas has led to greater growth in urban areas outside the city centre boundaries (Abdullah, 2012).

\section{CONCLUSIONS}

The paper provides an insight of the current trend and status of urban sprawl studies based on published literature through most used scientific databases. By doing so, the researcher was able to find most relevant and reliable sources of research information on urban sprawl to extract the issues and problem. Examining the issues and problems of this topic helps the researcher to find the most significant research gap, and the best solution can be explored. The author explores the Bibliometric analysis technique, which is the best known of sophisticated approaches, in evaluating the qualitative literature into quantitative assessment (Borgman \& Furner, 2002). This paper contributes to determining the research gaps for author's research on 'Developing Land Use Geospatial Indices (LUGI) in Measuring Urban Sprawl using GIS and Remote Sensing Techniques: Case Study of Kuala Lumpur."

\section{ACKNOWLEDGMENT}

The authors greatly acknowledge the support from IIUM. The authors also thank all the reviewers for their comments and suggestion for the improvement of this paper.

\section{REFERENCES}

Abdullah, J. (2012). City competitiveness and urban sprawl: their implications to socioeconomic and cultural life in Malaysian cities. Procedia - Social and Behavioral Sciences, $50,20-29$.

Allen, J., \& Lu, K. (2003). Modeling and prediction of future urban growth in the Charleston Region of South Carolina : a GIS-based integrated approach. Conservation Ecology, 8(2), 20. Retrieved from http://www.consecol.org

Almeida, B. (2005). A GIS Assessment of Urban Sprawl in Richmond, Virginia (Master's thesis). Virginia Polytechnic Institute and State University, Blacksburg, Virginia, USA.

Altieri, L., Cocchi, D., Pezzi, G., Scott, E. M., \& Ventrucci, M. (2014). Urban sprawl scatterplots for urban morphological zones data. Ecological Indicators, 36, 315-323.

Anas, A., \& Pines, D. (2008). Anti-sprawl policies in a system of congested cities. Regional Science and Urban Economics, 38(5), 408-423.

Anas, A., \& Rhee, H. J. (2006). Curbing excess sprawl with congestion tolls and urban boundaries. Regional Science and Urban Economics, 36(4), 510-541.

Apostolos, L. (2007). Fractal analysis of the urbanization at the outskirts of the city: models, measurement and explanation. Cybergeo, Article 391. Retrieved from https://cybergeo.revues.org/8902.

Arbury, J. (2005). From urban sprawl to compact city - an analysis of urban growth management in Auckland (Master's thesis). University of Auckland, Auckland, Australia. 
Ardeshiri, M., \& Ardeshiri, A. (2011). Sprawl or Compact City: The Role of Planners in Urbanization Processes in Developing Countries. Conference on Built and Natural Environment Research Papers. The British University, Egypt.

Arribas-Bel, D., Nijkamp, P., \& Scholten, H. (2011). Multidimensional urban sprawl in Europe: A self-organizing map approach. Computers, Environment and Urban Systems, $35(4), 263-275$.

Banzhaf, H. S., \& Lavery, N. (2010). Can the land tax help curb urban sprawl? Evidence from growth patterns in Pennsylvania. Journal of Urban Economics, 67(2), 169-179.

Barnes, K. B., Morgan, J. M., Roberge, M. C., \& Lowe, S. (2001). Sprawl Development: Its Patterns, Consequences, and Measurement (Technical report). Towson University, Baltimore, Maryland.

Belal, A. A., \& Moghanm, F. S. (2011). Detecting urban growth using remote sensing and GIS techniques in Al Gharbiya Governorate, Egypt. The Egyptian Journal of Remote Sensing and Space Science, 14(2), 73-79.

Bellis, N. De. (2009). Bibliometrics and citation analysis: from the science citation index to cybermetrics. Maryland, United States of America: The Scarecrow Press Inc.

Bhatta, B. (2010). Analysis of urban growth and sprawl from remote sensing data. New York: Springer-Verlag Berlin Heidelberg.

Bhatta, B., Saraswati, S., \& Bandyopadhyay, D. (2010a). Quantifying the degree-of-freedom, degree-of-sprawl, and degree-of-goodness of urban growth from remote sensing data. Applied Geography, 30(1), 96-111.

Bhatta, B., Saraswati, S., \& Bandyopadhyay, D. (2010b). Urban sprawl measurement from remote sensing data. Applied Geography, 30(4), 731-740.

Borgman, C. L., \& Furner, J. (2002). Scholarly communication and bibliometrics. Annual Review of Information Science and Technology, 36, 2-72.

Brueckner, J. K., \& Helsley, R. W. (2011). Sprawl and blight. Journal of Urban Economics, 69(2), 205-213.

Bruegmann, R. (2015). Urban sprawl. International encyclopaedia of the social \& behavioral sciences (Second Edi, Vol. 24). Elsevier.

Burchfield, M., Overman, H. G., Puga, D., \& Turner, M. a. (2006). Causes of sprawl: a portrait from space. The Quarterly Journal of Economics, 121(2), 587-633.

Campbell, D., Picard-Aitken, M., Cote, G., Caruso, J., Valentim, R., Edmonds, S., Archambault, E. (2010). Bibliometrics as a performance measurement tool for research evaluation: the case of research funded by the National Cancer Institute of Canada. American Journal of Evaluation, 31(1), 66-83.

Castracane, P., Iavarone, F., Mica, S., Sottile, E., Vignola, C., Arino, O., Pratesi, I. (2003) Monitoring urban sprawl and its trends with EO data. UrbEx, a prototype national service from a WWF-ESA joint effort. 2nd GRSS/ISPRS Joint Workshop on "Data Fusion and Remote Sensing over Urban Areas. (pp. 245-248).

Catalán, B., Saurí, D., \& Serra, P. (2008). Urban sprawl in the Mediterranean? Patterns of growth and change in the Barcelona Metropolitan Region 1993-2000. Landscape and Urban Planning, 85(3-4), 174-184.

Chorianopoulos, I., Pagonis, T., Koukoulas, S., \& Drymoniti, S. (2010). Planning, competitiveness and sprawl in the Mediterranean city: the case of Athens. Cities, 27(4), 249-259.

Coisnon, T., Oueslati, W., \& Salani, J. (2014). Urban sprawl occurrence under spatially varying agricultural amenities. Regional Science and Urban Economics, 44(1), 38-49.

Couch, C., \& Karecha, J. (2006). Controlling urban sprawl: Some experiences from Liverpool. Cities, 23(5), 353-363. 
Nur Aulia Rosni, Norzailawati Mohd Noor, \& Alias Abdullah

Bibliometric Analysis on Quantifying Urban Sprawl in Assessing a Comprehensive Meaning of Sprawl: A Review

Crawford, T. W. (2007). Where does the coast sprawl the most? Trajectories of residential development and sprawl in coastal North Carolina, 1971-2000. Landscape and Urban Planning, 83(4), 294-307.

Durieux, L., Lagabrielle, E., \& Nelson, A. (2008). A method for monitoring building construction in urban sprawl areas using object-based analysis of Spot 5 images and existing GIS data. ISPRS Journal of Photogrammetry and Remote Sensing, 63(4), 399 408.

E. E. A. (2006). Urban sprawl in Europe: The ignored challenge. Copenhagen.

Ewing, R. (1997). Is Los Angeles-style sprawl desirable? Journal of the American Planning Association, 63(1), 107.

Ewing, R. (2008). Characteristic, causes, and effects of sprawl: a literature review. In J. M. Marzluff, W. Endlicher, G. Bradley, U. Simon, E. Shulenberger, M. Alberti, ... C. ZumBrunnen (Eds.), Urban Ecology An International Perspective on the Interaction Between Humans and Nature (1st ed.), p. 829. New York: Springer.

Ewing, R., Hamidi, S., Grace, J. B., \& Dennis, Y. W. (2016). Does urban sprawl hold down upward mobility? Landscape and Urban Planning, 148, 80-88.

Ewing, R., Meakins, G., Hamidi, S., \& Nelson, A. C. (2014). Relationship between urban sprawl and physical activity, obesity, and morbidity - update and refinement. Health and Place, 26, 118-126.

Ewing, R., Pendall, R., \& Chen, D. (2002). Measuring sprawl and its impact. Smart growth America. Retrieved from http://www.smartgrowthamerica.org/ sprawlindex/sprawlindex.html

Farber, S., \& Li, X. (2013). Urban sprawl and social interaction potential: an empirical analysis of large metropolitan regions in the United States. Journal of Transport Geography, 31, 267-277.

Feng, L. (2008). Applying remote sensing and GIS on monitoring and measuring urban sprawl. A case study of China. International Journal of Applied Earth Observation and Geoinformation, 10(1), 47-56.

Feng, L., Du, P., Zhu, L., Luo, J., \& Adaku, E. (2015). Investigating sprawl along China's urban fringe from a spatio-temporal perspective. Applied Spatial Analysis and Policy, (September).

Galster, G., Hanson, R., Ratcliffe, M. R., Wolman, H., Coleman, S., \& Freihage, J. (2001). Wrestling sprawl to the ground: defining and measuring an elusive concept. Housing Policy Debate, 12(4), 681-717.

Gamba, P. (2009). Current trends in urban remote sensing. In Proceedings of the 30th Asian Conference on Remote Sensing, 6.

Gennaio, M. P., Hersperger, A. M., \& Burgi, M. (2009). Containing urban sprawl - evaluating effectiveness of urban growth boundaries set by the Swiss Land Use Plan. Land Use Policy, 26(2), 224-232.

Gerundo, R., \& Grimaldi, M. (2011). The measure of land consumption caused by urban planning. Procedia Engineering, 21, 1152-1160.

Gottlieb, P. D. (1999). Do economists have anything to contribute to the debate on urban sprawl? (And would anybody listen to them if they did?). Forum for Social Economics, 28(2), 51-64.

Haase, D., \& Nuissl, H. (2007). Does urban sprawl drive changes in the water balance and policy? Landscape and Urban Planning, 80(1-2), 1-13.

Hasse, J. E., \& Lathrop, R. G. (2003). Land resource impact indicators of urban sprawl Applied Geography, 23(2-3), 159-175. 
Hasse, J., \& Kornbluh, A. (2004). Measuring accessibility as a spatial indicator sprawl. Middle States Geographer, 37, 108-115.

Habibi, S., \& Asadi, N. (2011). Causes, results and methods of controlling urban sprawl Procedia Engineering, 21, 133-141.

Hammer, M. J., \& Witten, J. D. (2011). Conservation and development? Effectively packaging land protection tools to preserve farmland and manage growth. Tufts University. Retrieved from http://search.proquest.com/docview /879424533?accountid=13042 \nhttp://oxfordsfx.hosted.exlibrisgroup.com/oxford?url_v er=Z39.88-

2004\&rft_val_fmt=info:ofi/fmt:kev:mtx:dissertation\&genre=dissertations+\&+theses\&si $\mathrm{d}=$ ProQ:ProQuest+Dissertations+\&+Theses+Global\&a

Herold, M., Couclelis, H., \& Clarke, K. C. (2005). The role of spatial metrics in the analysis and modeling of urban land use change. Computers, Environment and Urban Systems, 29(4), 369-399.

Jaeger, J. A., Bertiller, R., Schwick, C., Cavens, D., \& Kienast, F. (2010). Urban permeation of landscapes and sprawl per capita: new measures of urban sprawl. Ecological Indicators, 10(2), 427-441.

Jaeger, J. A. G., Bertiller, R., Schwick, C., \& Kienast, F. (2010). Suitability criteria for measures of urban sprawl. Ecological Indicators, 10(2), 397-406.

Knaap, G., Song, Y., Ewing, R., \& Clifton, K. (2005). Seeing the Elephant : Multi-disciplinary Measures of Urban Sprawl. Retrieved from http://smartgrowth.umd.edu/multidisciplinarymeasuresurbansprawl.html.

Li, X., \& Yeh, A. G.-O. (2004). Analyzing spatial restructuring of land use patterns in a fast growing region using remote sensing and GIS. Landscape and Urban Planning, 69(4), 335-354.

Majid, M. R., \& Yahya, H. (2010). Sprawling of a Malaysian city: what type and what solutions? The First International Conference on Sustainable Urbanization (ICSU 2010), Kowloon, Hong Kong.

Majid, M. R., \& Yahya, H. (2011). Urban Sprawl In Malaysia : Is Compact Development The Answer? Johor Bahru, Malaysia.

Nechyba, T. J., \& Walsh, R. P. (2004). Urban sprawl. Journal of Economic Perspectives, 18(4), 177-200.

Ngoran, S. D., \& Xue, X. (2015). Addressing urban sprawl in Douala, Cameroon: Lessons from Xiamen integrated coastal management. Journal of Urban Management, 4, 53-72.

Olujimi, J. (2009). Evolving a planning strategy for managing urban sprawl in Nigeria. Journal of Human Ecology, 25(3), 201-208.

Osman, S., Nawawi, A. H., \& Abdullah, J. (2008). Urban sprawl and its financial cost : - a conceptual framework. Asian Social Science, 4, 39-50.

Rajeshwari. (2006). Management of the urban environment using remote sensing and geographical information systems. Journal of Human Ecology, 20(4), 269-277.

Ramachandra, T. V., Bharath, a. H., \& Sowmyashree, M. V. (2014). Monitoring urbanization and its implications in a mega city from space: Spatiotemporal patterns and its indicators. Journal of Environmental Management, 148, 67-81.

Reuters, T. (2008). Whitepaper using Bibliometrics: a guide to evaluating research performance with citation data. Thomson Reuters.

Russell, J. M., \& Rousseau, R. (2010). Bibliometrics and institutional evaluation. Encyclopaedia of Life Support Systems (EOLSS), Part 19.3 Science and Technology Policy. UNESCO/EOLSS Publishers. 
Nur Aulia Rosni, Norzailawati Mohd Noor, \& Alias Abdullah

Bibliometric Analysis on Quantifying Urban Sprawl in Assessing a Comprehensive Meaning of Sprawl: A Review

Steil, L., Salingaros, N. A., \& Mehaffy, M. W. (2007). Growing sustainable suburbs : an incremental strategy for reconstructing sprawl. In T. Haas (Ed.), New Urbanism and beyond: contemporary and future trends in urban design, pp. 1-25. Rizzoli.

Tanguay, G. a., Rajaonson, J., Lefebvre, J. F., \& Lanoie, P. (2010). Measuring the sustainability of cities: An analysis of the use of local indicators. Ecological Indicators, 10(2), 407-418.

Terzi, F., \& Kaya, H. S. (2008). Analyzing urban sprawl patterns through fractal geometry: the case of Istanbul Metropolitan Area (CASA Working Paper No. 144). London: Centre for Advanced Spatial Analysis (UCL).

Theobald, D. M. (2003). Defining and mapping rural sprawl: examples from the Northwest $U S^{*}$. Fort Collins, CO: Growth Management Leadership Alliance white paper.

Travisi, C. M., Camagni, R., \& Nijkamp, P. (2009). Impacts of urban sprawl and commuting: a modelling study for Italy. Journal of Transport Geography, 18(3), 382-392.

Tsai, Y.-H. (2005). Quantifying urban form: compactness versus "sprawl." Urban Studies, 42(1), 141-161.

Verbeek, T., Boussauw, K., \& Pisman, A. (2014). Presence and trends of linear sprawl Explaining ribbon development in the north of Belgium. Landscape and Urban Planning, $128,48-59$

Vyn, R. J. (2012). Examining for evidence of the leapfrog effect in the context of strict agricultural zoning. Land Economics, 88, 457-477.

Wassmer, R. W. (2007). Causes of urban sprawl in the United States: auto reliance as compared to natural evolution, flight from blight, and local revenue reliance. Journal of Policy Analysis and Management, 27(3), 536-555.

Weng, Q. (2001). A remote sensing - GIS evaluation of urban expansion and its impact on surface temperature in the Zhujiang Delta, China. International Journal Remote Sensing, 22(10), 1999-2014.

Wilson, E. H., Hurd, J. D., Civco, D. L., Prisloe, M. P., \& Arnold, C. (2003). Development of a geospatial model to quantify, describe and map urban growth. Remote Sensing of Environment, 86(3), 275-285.

$\mathrm{Wu}$, J. (2006). Environmental amenities, urban sprawl, and community characteristics. Journal of Environmental Economics and Management, 52(2), 527-547.

Wu, Q., Li, H., Wang, R., Paulussen, J., He, Y., Wang, M., Wang, Z. (2006). Monitoring and predicting land use change in Beijing using remote sensing and GIS. Landscape and Urban Planning, 78(4), 322-333.

Yeh, A. G. O. (2000). Urban form and density in sustainable development. Retrieved from http://www.urbandensity.org/urban-form-and-density-sustainable-development.

Yeh, A. G. O., \& Li, X. (1999a). Measurement of urban sprawl in a rapid growing region using entropy. In Proceedings of the International Symposium on Digital Earth (pp. 1-5). Hong Kong: Science Press.

Yeh, A. G. O., \& Li, X. (1999b). An entropy method to analyze urban sprawl in a rapid growing region using TM images. In Proceedings of the 20th Asian Conference on Remote Sensing (pp. 542-547). 